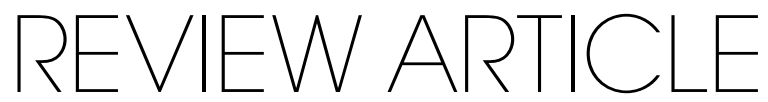

\title{
The role of genetic testing in unexplained sudden death
}

\author{
CHRIS J. MILES, and ELIJAH R. BEHR \\ LONDON, UK
}

\begin{abstract}
Most sudden deaths are because of a cardiac etiology and are termed sudden cardiac death (SCD). In younger individuals coronary artery disease is less prevalent and cardiac genetic disorders are more common. If sudden death is unexplained despite an appropriate autopsy and toxicologic assessment the term sudden arrhythmic death syndrome (SADS) may be used. This is an umbrella term and common underlying etiologies are primary arrhythmia syndromes with a familial basis such as Brugada syndrome, long QT syndrome, and subtle forms of cardiomyopathy. The first clinical presentation of these conditions is often SCD, which makes identification, screening, and risk stratification crucial to avert further deaths. This review will focus on genetic testing in the context of family screening. It will address the role of the "molecular autopsy" alongside current postmortem practices in the evaluation of SADS deaths. We describe the current data underlying genetic testing in these conditions, explore the potential for next-generation sequencing, and discuss the inherent diagnostic problems in determination of pathogenicity. (Translational Research 2015; [:1-15)
\end{abstract}

\begin{abstract}
Abbreviations: $\mathrm{AHA}=$ American Heart Association; $\mathrm{ARVC}=$ arrhythmogenic right ventricular cardiomyopathy; $\mathrm{BrS}=$ Brugada syndrome; ChIP = channel interacting protein; CPVT = catecholaminergic polymorphic ventricular tachycardia; DCM = dilated cardiomyopathy; EHRA = European Heart Rhythm Association; ERS = early repolarization syndrome; $\mathrm{HCM}=$ hypertrophic cardiomyopathy; HRS = Heart Rhythm Society; IVF = idiopathic ventricular fibrillation; LQTS = long QT syndrome; PCCD = premature cardiac conduction disease; SADS = sudden arrhythmic death syndrome; SCD = sudden cardiac death; SNR = signal-to-noise ratio; SQTS = short QT syndrome; SUDS = sudden unexpected death syndrome; VUS = variant of unknown significance
\end{abstract}

From the Division of Clinical Sciences, Cardiovascular Sciences Research Centre, St George's University of London, London, UK.

Submitted for publication January 1, 2015; revision submitted June 8, 2015; accepted for publication June 11, 2015.

Reprint requests: Elijah R. Behr, Division of Clinical Sciences, Cardiovascular Sciences Research Centre, St George's University of London, Cranmer Terrace, London SW17 0RE, UK; e-mail: ebehr@sgul. ac.uk.

$1931-5244 / \$$ - see front matter

(c) 2015 Elsevier Inc. All rights reserved.

http://dx.doi.org/10.1016/j.trs1.2015.06.007

\section{INTRODUCTION}

$\mathbf{T}$ he estimated incidence of sudden cardiac death (SCD) in the general population in Europe and the United States (US) is between 50 and 100 per 100,000 per annum. ${ }^{1-3}$ SCD claims 300,000 400,000 deaths per annum in the $\mathrm{US}^{4,5}$ and there were an estimated 70,000 SCDs in the UK in 2010, most because of ischemic events. ${ }^{6}$ SCD is usually defined as an unheralded witnessed instantaneous death but it may also be described as being preceded by a prodrome of acute cardiac symptoms up to 1 hour before death. ${ }^{5}$ Unwitnessed cases without a prior deterioration in the preceding 12-24 hours may also be included. Estimates vary, however, because of a dependence on the presence 
of autopsied vs nonautopsied cases and the variability of definitions and the duration of prodromal symptoms before the terminal event. A national prospective survey of English coroners' cases for more than a 20-month period in the late 1990s evaluated sudden deaths in Caucasians aged 4-64 years with no history of cardiac disease, negative toxicology, and last seen alive within 12 hours of death. A normal coroner's autopsy and subsequent evaluation of the heart by a cardiac pathologist established these as sudden arrhythmic death syndrome (SADS) cases with an estimated incidence of up to 1.38 per 100,000 per annum.

SCD in the young. In individuals aged $<35$ years inherited cardiac diseases are more prevalent and estimates of the incidence of SCD vary depending on definitions and study site. For example, a Danish nationwide analysis of deaths from 2000 to 2006 revealed an annual incidence of young SCD of 2.8 per $100,000,{ }^{7}$ whereas a retrospective US study of $>6$ million military recruits reported an incidence as high as 13 per 100,000 per annum. ${ }^{8}$ Puranik et $\mathrm{al}^{9}$ retrospectively reviewed pathologic reports from 427 autopsied sudden death cases aged 5-35 years at a forensic medical facility from 1995 to 2004 in Sydney. The most common cardiac cause of death was presumed arrhythmia in those with no (or minimal) structural heart disease (29\%), that is, SADS. Retrospective analysis of death certification, autopsy reports, and registry data estimated that $31 \%$ of autopsied SCD cases in Danes aged 1-49 years were unexplained and attributed to SADS. ${ }^{10}$

Conversely, in 79\% of 197 cases of young SCD in Italy, histologic analysis yielded a structural diagnosis such as cardiomyopathy or focal myocarditis; 6\% were unexplained and attributable to SADS. ${ }^{11}$ In the Veneto region of Italy, studies have implicated arrhythmogenic right ventricular cardiomyopathy (ARVC) in $20 \%$ of sudden deaths among athletes and the young. ${ }^{12}$ Maron et $\mathrm{al}^{13}$ described sudden deaths in young competitive athletes for more than a 27 -year period in the US: $56 \%$ were because of cardiovascular disease, the most common cause (36\%) being hypertrophic cardiomyopathy (HCM).

In the UK the incidence of cardiac death in the young ( $\leq 35$ years) as determined by analysis of Office for National Statistics data was 1.8 per 100,000 in England and Wales (2002-2005). Critical appraisal estimated the incidence of SADS as 0.24 per 100,000 per annum, significantly higher than the 0.1 per 100,000 reported by the Office for National Statistics as instantaneous unexplained sudden death, but still less than most other estimates. ${ }^{14}$ This is likely to be because of misclassification of the cause of death as mortality data are largely derived from death certificate documentation that may under-report the true incidence of cardiac arrhythmia. For example, in one study a significant proportion (23\%) of unexplained drowning cases carried mutations associated with arrhythmia syndromes, ${ }^{15}$ and certification of sudden death in epilepsy may overlook cases, which result from a primary arrhythmic cause. ${ }^{16,17}$

\section{DEFINING SADS}

A consensus statement from the Heart Rhythm Society (HRS), European Heart Rhythm Association (EHRA), and the Asia Pacific HRS defines SADS as a pathologic diagnosis of exclusion after postmortem cardiac investigation and toxicologic analysis. ${ }^{18}$ Even if nondiagnostic pathology is detected, cases should still be considered as SADS because of the high chance of underlying inherited ion channel disease. ${ }^{19}$ Expert autopsy is also recommended as general pathologists may misdiagnose cases, over diagnosing ARVC, and under diagnosing SADS. ${ }^{20}$ Guidelines for autopsy practice exist and include detailed description of postmortem sampling techniques with integration of specialist skills in the evaluation of possible familial disorders. $^{21,22}$ In the US, the state-wide Sudden Death in the Young Registry collates young SCD case data, using DNA analysis in a subset of cases for the purpose of further evaluation and future research. ${ }^{23}$ Unfortunately, access to expert cardiac pathology is very much limited internationally.

\section{DIAGNOSTIC APPROACHES AND GENETIC TESTING}

Two approaches may be taken to make a diagnosis in a family: familial clinical evaluation with genetic testing targeted to phenotype and postmortem genetic testing "the molecular autopsy." The overall aim is to identify cardiac genetic disease were present and institute preventative treatment were necessary to avert further SCD. ${ }^{24}$ The clinical role of genetic testing is therefore a diagnostic one and dependent on identifying mutations, that is, disease-causing or pathogenic rare genetic variants. The rapid development in sequencing technology has, however, led to the identification of frequent rare genetic variation in both healthy and affected individuals. Rare variants are often private to a specific family and therefore may be unknown in the literature. Their associated risk for disease causation and therefore their clinical significance is often uncertain and a major challenge as incorrect inferences of causality can have serious implications for diagnosis and management of families. If pathogenicity of a rare variant remains uncertain then it is termed a "variant of unknown significance" (VUS). ${ }^{25}$ 


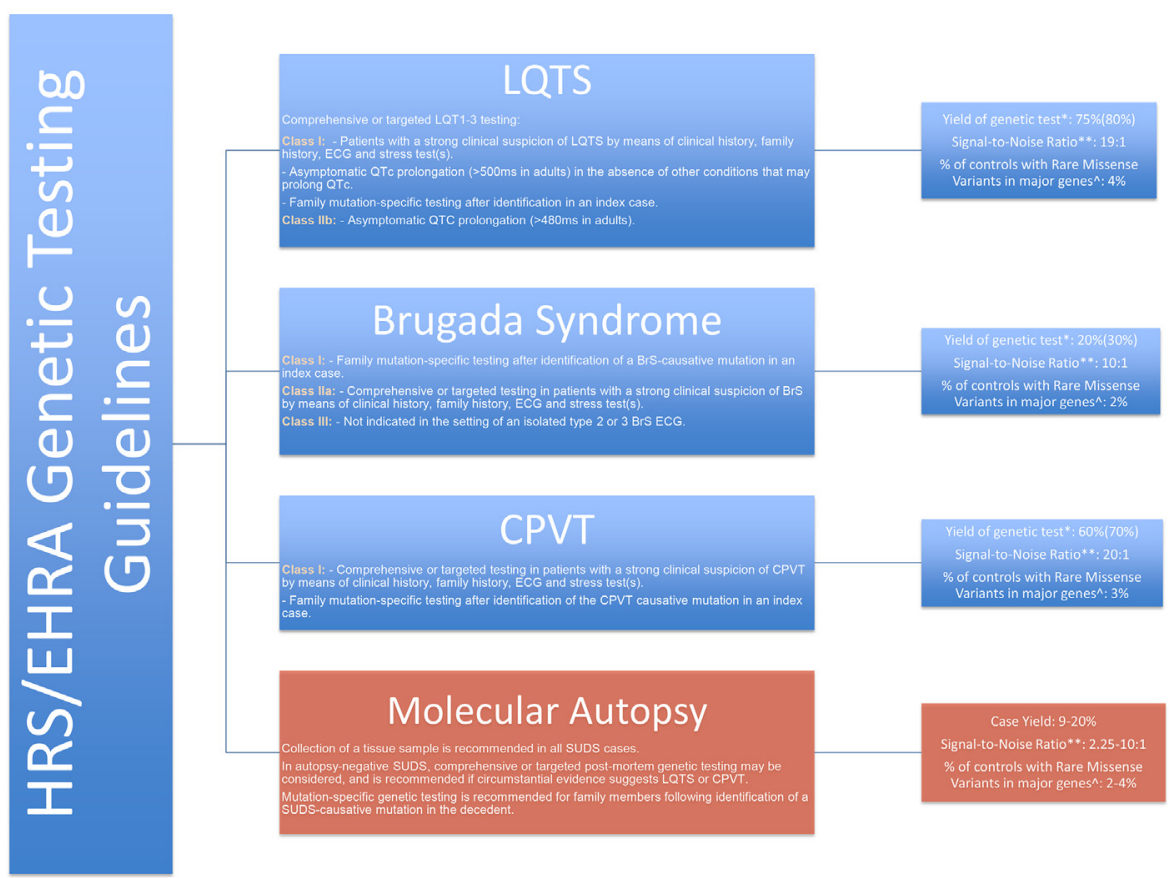

Fig 1. Guidelines for genetic testing in the channelopathies and diagnostic utility based on the signal-to-noise ratio. Estimates for molecular autopsy are based on the studies analyzed in this review. Adapted from the HRS and EHRA Genetic Testing Guidelines. ${ }^{27}$ *Yield of diagnostic test—proportion of patients with positive genotyping, derived from unrelated cases. The first number is the yield when a major gene has been targeted. The number in parenthesis is the total when including all disease-associated genes. **Signal-to-noise ratio-estimate of positive predictive value, devised by dividing the case yield of rare variants by the background control rate of rare missense variants among major genes. Rare missense variants-possible disease-causing mutations determined by a percentage of rare amino acid substitutions in the major disease-associated genes. BrS, Brugada syndrome; CPVT, catecholaminergic polymorphic ventricular tachycardia; ECG, electrocardiogram; EHRA, European Heart Rhythm Association; HRS, Heart Rhythm Society; LQTS, long QT syndrome; SUDS, sudden unexpected death syndrome.

The presence in healthy normal people of rare variants, usually missense, is described as genetic "background noise" (ie, the frequency of rare variants within a particular gene in the healthy population). ${ }^{26}$ The ratio of rare variant yield in cases (also mainly missense) to background noise is known as the "signal-to-noise ratio" (SNR) (Fig 1). Various methods for assessing likelihood of pathogenicity of rare variants have evolved as follows. ${ }^{28,29}$

Absence of the variant in a healthy control population. Before the extent of rare genetic variation in the genome was appreciated, most research studies and laboratory reports presumed pathogenicity on the basis of absence in a control population. Although the presence of a rare variant in the general population is helpful in reducing the chance of it being directly causative, novelty no longer carries much weight. Nonetheless, it is the first step in assessing likelihood of pathogenicity and increasingly large reference databases are available such as the Exome Aggregation Consortium with exome data from more than 60,000 unrelated individuals. ${ }^{30}$
Cosegregation of phenotype with genotype in large families. This is the process of associating a variant with disease in a family by identification of the variant in all affected individuals. This assists in determining the likelihood of causality, although if one affected relative does not carry the variant then it cannot be used as a clinical test. In practice, however, this approach is often not feasible because of small family sizes and the possibility of association by chance. The detection of a de novo rare variant in an associated gene in an affected child with unaffected parents does, however, support strongly the likely pathogenicity of the variant.

Severity of the type of mutation, that is, nonsense vs missense. In general, the likelihood of a functional effect of a variant on a protein is increased the more "radical" the associated DNA change is. Nonsynonymous single nucleotide changes, that is missense mutations, are common and are found in both healthy unaffected and affected individuals and are most difficult to assess (see aforementioned). Mutations because of deletions or insertions and some splice-site mutations may lead to abnormal protein products and 
protein truncations. These "nonsense" mutations are less common and less likely to be present in unaffected individuals. Causation is therefore less difficult to determine. For example, premature truncation SCN5A mutations have been linked to severity of disease and are highly likely to be pathogenic because of haploinsufficiency. ${ }^{31}$ However, although truncating variants of the gene titin (TTN) are associated with dilated cardiomyopathy (DCM), ${ }^{32}$ they are also present in unaffected controls and represent a diagnostic challenge. ${ }^{33}$

Prior and reliable description in the literature. It can be helpful if a variant has previously been associated with disease in another proband and their family. Unfortunately not all prior reports are robust. Previously published rare variants postulated to be mutations have since been determined to be present in population databases at too high a frequency to be causative of disease. $^{34,35}$ They may represent functionally active variants that modify disease expression or otherwise are nonfunctional population variants. For example, one study examined an established exome database and compared it with a catalog of 197 variants reported as causative of DCM; $16.8 \%$ of the variants reported as causative were also present in the exome database, although functional data suggested that a significant proportion may have been lower penetrance disease-causing alleles. ${ }^{36}$ Another study of childhood recessive diseases suggested $27 \%$ of mutations previously cited as pathogenic are in fact common polymorphisms or misinterpreted variants. ${ }^{37}$

Amino acid conservation and in silico methods. Missense mutations result in an amino acid changes that may have varying differences of side chain size, polarity, and lipophilicity compared with the wildtype protein. The greater the difference is the more likely that a structural and/or functional change will occur. In addition, the amino acid may be at a critical part of the protein that is conserved in other human proteins with similar functional domains (paralogs) or the same protein in other species (orthologs). Measures of conservation of amino acids and therefore likelihood of disease causation because of an amino acid change have been assessed by algorithms such as the Grantham conservation score. ${ }^{38}$ These methods have also been incorporated into a number of different in silico tools that can also use predicted protein structural changes to infer causation. In combination, they can be effective in assisting assessment of pathogenicity of rare variants in $K C N Q 1$ and $K C N H 2$ in long QT syndrome (LQTS) ${ }^{39}$ and to lesser extent SCN5A variants in LQTS and Brugada syndrome $(\mathrm{BrS}){ }^{40}$ They are, however, unreliable as sole evidence of pathogenicity in the clinical setting.
Functional expression studies of the variant's biophysical effect. The consequences of mutations can be studied in RNA expression systems and functional models such as ion channel expression studies, animal models, and induced pluripotent stem cell-derived cardiomyocytes. Unfortunately, these are generally costly and are not feasible for routine evaluation of genetic findings.

To optimize and standardize assessment, Campuzano et al have recently proposed a scoring system to determine the pathogenicity of genetic variants associated with the arrhythmia syndromes combining data from the previously mentioned methods. A scoring range from 0 to 15 categorized variants into separate groups, including benign, VUS, and pathogenic. ${ }^{41}$ This sort of approach may enable better classification of variants in the future.

Determining the causation of disease in families can be further complicated by other genetic variants that can influence phenotype may also be responsible, known as digenic or oligogenic inheritance. For example, 5\%-10\% of LQTS patients have mutations in 2 or more of the known genes, which can influence disease expression. ${ }^{42}$

\section{CAUSES OF SADS AND THE ROLE OF GENETIC TESTING}

Arrhythmia syndromes (or cardiac channelopathies) are a heterogeneous group of conditions that are usually hereditary and are associated with an apparently structurally normal heart. They are often caused by mutations in genes encoding cardiac ion channel subunits and channel interacting proteins (Table I). The channelopathies include LQTS, BrS, catecholaminergic polymorphic ventricular tachycardia (CPVT), short QT syndrome, idiopathic ventricular fibrillation, early repolarization syndrome, premature cardiac conduction disease, and others. These are described in Table I. LQTS has the highest yield from testing (approximately 75\%), with wide variation among the other channelopathies (20\% in the $\mathrm{BrS}) .^{25}$ In some cases, despite a normal heart being found at autopsy, cardiomyopathy is detected during clinical evaluation of the family. Thus, disease insufficient to cause histopathologic changes detectable even at expert autopsy may still cause or predispose toward SCD. ${ }^{70}$ We focus on the main phenotypes of interest subsequently.

Long QT syndrome. Congenital LQTS has a prevalence of approximately $1: 2000^{71}$ and is characterized by prolongation of the QT interval on the electrocardiogram (ECG) and increased risk of the characteristic ventricular arrhythmia, Torsades de Pointes, and SCD. Hundreds of mutations in 14 genes $^{25}$ predominantly encoding components and channel interacting proteins of repolarizing potassium currents and the sodium channel current (Nav1.5) have been identified (Table I). 
Table I. Genes associated with ion channel diseases and their associated phenotypes and frequencies

\begin{tabular}{|c|c|c|c|c|c|}
\hline Clinical syndrome & Gene & $\begin{array}{l}\text { Ion channel } \\
\text { component }\end{array}$ & $\begin{array}{l}\text { Effect of } \\
\text { mutation }\end{array}$ & $\begin{array}{l}\text { Ion channel } \\
\text { disease }\end{array}$ & $\begin{array}{l}\text { Frequency in phenotype } \\
\text { (+reference) }\end{array}$ \\
\hline \multirow[t]{13}{*}{ Brugada syndrome } & SCN5A & $\alpha$ Subunit /Na & Loss of function & $\mathrm{BrS} 1$ & $20 \%-30 \%{ }^{40}$ \\
\hline & GPD1L & INa ChIP & Loss of function & $\mathrm{BrS} 2$ & $<1 \%{ }^{43}$ \\
\hline & CACNA1C & $\alpha$ Subunit /Ca & Loss of function & $\mathrm{BrS3}$ & BrS $2 \%-12 \%{ }^{43-45}$ \\
\hline & CACNB2 & $\beta$ Subunit /Ca & Loss of function & $\mathrm{BrS} 4$ & BrS $2 \%-12 \%{ }^{43-45}$ \\
\hline & SCN1B & $\beta$ Subunit $/ \mathrm{Na}$ & Loss of function & BrS5 & $<1 \%{ }^{43}$ \\
\hline & KCNE3 & $\beta$ Subunit /Ks//to & Gain of function & $\mathrm{BrS6}$ & $<1 \%{ }^{43}$ \\
\hline & SCN3B & $\beta$ subunit $/ \mathrm{Na}$ & Loss of function & $\mathrm{BrS7}$ & $<1 \%{ }^{43}$ \\
\hline & HCN4 & If & Loss of function & $\mathrm{BrS} 8$ & $N A^{46}$ \\
\hline & KCNJ8 & $\alpha$ Subunit IKATP & Gain of function & BrS9 & $<1 \%$ \\
\hline & CACNA2D1 & $\alpha 2 \mathrm{~d}$ subunit /Ca & Loss of function & $\mathrm{BrS} 10$ & BrS $2 \%-12 \%{ }^{43-45}$ \\
\hline & KCND3 & $\alpha$ subunit /to & Gain of function & $\mathrm{BrS} 11$ & $<1 \%{ }^{43}$ \\
\hline & MOG1 & INa ChIP & Loss of function & BrS12 & $<1 \%{ }^{43}$ \\
\hline & SLMAP & INa ChIP & Loss of function & $\mathrm{BrS13}$ & $\mathrm{NA}^{47}$ \\
\hline \multirow[t]{14}{*}{ Long QT syndrome } & KCNQ1 & $\alpha$ Subunit /Ks & Loss of function & LQT1 & $40 \%-55 \%{ }^{48}$ \\
\hline & $\mathrm{KCNH} 2$ & $\alpha$ Subunit $/ \mathrm{Kr}$ & Loss of function & LQT2 & $35 \%-45 \%{ }^{48}$ \\
\hline & SCN5A & $\alpha$ Subunit /Na & Gain of function & LQT3 & $2 \%-8 \%{ }^{48}$ \\
\hline & ANK2 & INa,K, INCX ChIP & Loss of function & LQT4 & $<1 \%{ }^{48}$ \\
\hline & KCNE1 & $\beta$ Subunit /Ks & Loss of function & LQT5 & $<1 \%{ }^{48}$ \\
\hline & KCNE2 & $\beta$ Subunit $/ \mathrm{Kr}$ & Loss of function & LQT6 & $<1 \%{ }^{48}$ \\
\hline & KCNJ2 & $\alpha$ Subunit /K1 & Loss of function & LQT7 (CPVT-like) & $<1 \%{ }^{48}$ \\
\hline & CACNA2D1 & $\alpha 2 \mathrm{~d}$ Subunit /Ca & Gain of function & LQT8 & $<1 \%{ }^{48}$ \\
\hline & CAV3 & INa ChIP & Gain of function & LQT9 & $<1 \%{ }^{48}$ \\
\hline & $S C N 4 B$ & $\beta$ Subunit $/ \mathrm{Na}$ & Gain of function & LQT10 & $<0.1 \%^{48}$ \\
\hline & AKAP9 & IKs ChIP & Loss of function & LQT11 & $<0.1 \%^{48}$ \\
\hline & SNTA1 & /Na ChIP & Gain of function & LQT12 & $<0.1 \%{ }^{48}$ \\
\hline & KCNJ5 & $\alpha$ Subunit /KAch & Loss of function & LQT13 & $N A^{49}$ \\
\hline & CALM1/CALM2 & SR Ca regulation & Loss of function & LQT14 & $N A^{50}$ \\
\hline \multirow[t]{4}{*}{ CPVT } & RYR2 & $\alpha$ Subunit & Loss of function & CPVT1 & $50 \%^{51}$ \\
\hline & CASQ2 & SR Ca regulation & Loss of function & CPVT2 & $N A^{52}$ \\
\hline & TRDN & SR Ca regulation & Loss of function & CPVT4 & $N A^{53}$ \\
\hline & CALM1 & SR Ca regulation & Loss of function & CPVT5 & $\mathrm{NA}^{54}$ \\
\hline \multirow[t]{15}{*}{ Other syndromes } & KCNQ1 & $\alpha$ Subunit /Ks & Gain of function & SQT2, FAF & $N A^{55,56}$ \\
\hline & KCNH2 & $\alpha$ Subunit $/ \mathrm{Kr}$ & Gain of function & SQT1 & $N A^{57}$ \\
\hline & KCNE2 & $\beta$ Subunit $/ \mathrm{Kr}$ & Gain of function & FAF & $N A^{58}$ \\
\hline & KCNJ2 & $\alpha$ Subunit /K1 & Gain of function & SQT3, FAF & $N A^{57,59}$ \\
\hline & KCNJ8 & $\alpha$ Subunit /KATP & Gain of function & ERS & $N A^{60,61}$ \\
\hline & DPP6 & to & Gain of function & IVF & $N A^{62}$ \\
\hline & HCN4 & If & Loss of function & SSS & $N A^{63}$ \\
\hline & CACNA1C & $\alpha$ Subunit /Ca & Loss of function & ERS & NA \\
\hline & CACNB2 & $\beta$ Subunit /Ca & Loss of function & ERS & NA \\
\hline & CACNA2D1 & $\alpha 2 \mathrm{~d}$ Subunit /Ca & Loss of function & ERS & NA \\
\hline & SCN5A & $\alpha$ Subunit $/ \mathrm{Na}$ & Loss of function & PCCD & $\mathrm{NA}^{64}$ \\
\hline & & & & ERS & $\pm 6 \%^{65}$ \\
\hline & & & & SSS & $2 \%-3 \%{ }^{66}$ \\
\hline & & & Mixed effect & Overlap & $\mathrm{NA}^{67,68}$ \\
\hline & & & Gain of function & MEPPC & $N A^{69}$ \\
\hline
\end{tabular}

Abbreviations: BrSX, Brugada syndrome subtype X; ChIP, channel interacting protein; CPVT, catecholaminergic polymorphic ventricular tachycardia; ERS, early repolarization syndrome; $F A F$, familial atrial fibrillation; ICa, depolarizing inward calcium current (slow); If, funny current; IKI, Kir2. 1 inward rectifying current; IKACH, acetylcholine-sensitive inward rectifying potassium current; IKATP, ATP-sensitive potassium channel; IKr, repolarizing outward rapid rectifying potassium current; IKS, repolarizing outward slow rectifying potassium current; INa, depolarizing inward sodium current (fast) Nav 1.5; INCX, sodium-calcium exchanger-associated current; Ito, transient outward potassium current; IVF, idiopathic ventricular fibrillation; $L Q T X$, long QT syndrome subtype X; MEPPC, multifocal ectopic Purkinje-related premature contractions; NA, not ascertained or applicable; $P C C D$, premature cardiac conduction disease; SQTX, short QT syndrome subtype X; SR Ca, sarcoplasmic reticulum calcium; SSS, sick sinus syndrome. Adapted from Wilde and Behr. ${ }^{25}$

Approximately $75 \%$ of patients with the syndrome have mutations in 1 of 3 "major" LQTS genes, the potassium channel genes KCNQ1 (LQT1, 35\%) and
KCNH2 (LQT2, 30\%) and the sodium channel gene SCN5A (LQT3, 10\%). ${ }^{72}$ With a background genetic "noise" level of $2 \%-4 \%$ for major genes, this gives a 
relatively favorable SNR. The 2011 HRS and EHRA Expert Consensus Statement therefore recommends comprehensive or LQT1-3 targeted LQTS genetic testing for any patient meeting diagnostic criteria (Fig 1). ${ }^{28}$ The 2013 diagnostic guidelines include carriers of a pathogenic mutation as being affected, regardless of clinical features. ${ }^{27}$ Genotype can be associated with phenotypic differences in clinical presentation and may be important in the SADS victim's presentation: LQT1 with exercise (especially swimming) and high emotional states; LQT2 with sudden arousal and acoustic triggers; and LQT3 with rest or sleep. ${ }^{72}$

The less common or "minor" LQTS genes have been associated with phenotype in small studies with low yields and small control groups. In some cases linkage is not available and causality rests on functional data and absence in a control. For example, the original description of $C A V 3$ as the cause of LQT9 has been questioned in subsequent follow-up studies. ${ }^{73}$ Background rare variation increases when the minor genes are included in testing panels but with little increase in yield. This makes the SNR less favorable and result less readily interpretable.

Brugada syndrome. BrS is diagnosed by the presence of at least $2 \mathrm{~mm}$ of coved ST increase with T wave inversion in at least one of the standard and high intercostal space right ventricular ECG leads: the type 1 ECG pattern. ${ }^{18,74}$ This pattern can be concealed and often dynamic, unmasked by factors such as sleep ${ }^{75}$ and pyrexia, ${ }^{76}$ as well as provoked by sodium channel blocking drugs such as ajmaline, procainamide, and flecainide. ${ }^{77}$ It can manifest with syncope because of polymorphic ventricular tachycardia, ultimately predisposing to ventricular fibrillation and SCD, which is commonly the first presentation. ${ }^{78}$ The prevalence of a BrS type $1 \mathrm{ECG}$ is higher in Asian countries, approximately $0.15 \%$ in adults. This is compared with $<0.02 \%$ in a Western population. ${ }^{79}$

$\mathrm{BrS}$ is a heterogeneous condition with reduced genetic penetrance. Recent evidence has suggested variable clinical phenotypes, where the syndrome may overlap with structural conditions such as ARVC. ${ }^{80}$ Inheritance can be autosomal dominant with variable expressivity or sporadic, ${ }^{81}$ as such, most individuals can remain asymptomatic throughout their lifetime. Recent evidence has also supported an oligogenic inheritance pattern. ${ }^{82}$ The most commonly affected gene is the SCN5A gene (approximately $20 \%$ of $\mathrm{BrS}$ cases, $\mathrm{BrS}^{83}$ ). More than 300 mutations of SCN5A have been described ${ }^{84}$ leading to loss of function because of a reduction in the amplitude of the sodium channel current by reduced expression and/or altered voltage-gating properties. ${ }^{85}$ Conversely, although gain-of-function SCN5A mutations are found in
LQT3, an overlap in phenotype exists between $\mathrm{BrS}$ and LQTS, both having been described in large families. ${ }^{67}$ In addition, there are large SCN5A positive families that have affected individuals who are noncarriers, suggesting a modifier role rather than direct causation in these pedigrees. ${ }^{86}$

Many other genes have been associated with the syndrome (Table I). One study identified mutations of the L-type calcium channel (encoded by CACNAIC, $C A C N B 2 B$, and $C A C N A 2 D 1$ ) in $10 \%-15 \%$ of $\mathrm{BrS}$ cases. ${ }^{44}$ The clinical phenotype also demonstrated a short QT interval. This has not been replicated by a follow-up study and the rest of these candidate genes account for very small numbers of cases. ${ }^{43}$ Other than GPDIL and SCNB1, these have not demonstrated genetic linkage in pedigrees. ${ }^{22} \mathrm{~A}$ recent study has also implicated SCN1OA, which encodes the neuronal current Nav1.8, as being responsible for a significant proportion of BrS cases. ${ }^{87}$ This has not been confirmed in a similar study of SCN5A negative BrS patients. Great caution must therefore be used in assessing rare variants in these low frequency genes.

Thus, the overall SNR level and potential for oligogenic inheritance are relatively unfavorable for diagnostic testing and recommendations are not as strong as in LQTS. Genetic testing can be useful in known or suspected cases of $\mathrm{BrS}$, but a positive test adds little to the on-going clinical management. It is, however, recommended for assessing relatives (Fig 1). ${ }^{27}$

Catecholaminergic polymorphic ventricula tachycardia. CPVT is a rare inherited arrhythmic disorder first described in $1975,{ }^{88}$ typically presenting within the first decade of life. Prevalence is estimated in 1:10,000 and individuals are at risk of SCD by means of catecholamine-induced polymorphic and bidirectional VT. ${ }^{89}$ The mechanism of arrhythmia in CPVT is chiefly because of intracellular calcium mishandling, where mutations in the RYR2 gene cause uncontrolled calcium release from the sarcoplasmic reticulum during diastole. ${ }^{90}$ The initial clinical manifestation is typically syncope associated with exercise or acute stress; however, SCD can be its sole presentation. The heart structure and resting ECG is often unremarkable in CPVT, necessitating use of exercise or catecholamine stress testing to capture arrhythmias, most commonly bidirectional VT. ${ }^{27}$

CPVT principally arises from mutations in 2 genes: CPVT1-RYR2 (encodes the cardiac ryanodine receptor channel) and CPVT2-CASQ2 (encodes calsequestrin, responsible for buffering calcium in the sarcoplasmic reticulum). ${ }^{91}$ CPVT has been described in small numbers of $K C N J 2, A N K B$, and $C A L M 1 / 2$ carriers, genes that have also been associated with LQTS. ${ }^{92}$ The condition is inherited with high penetrance in either 
an autosomal dominant (RYR2) or recessive (CASQ2) fashion, the former being more common affecting $55 \%-65 \%$ of probands, with CASQ2 only affecting a small number of cases but increasing the likelihood of earlier symptom onset. ${ }^{91}$ More than 100 mutations of $R Y R 2$ have been linked to CPVT1, the autosomal dominant form, which affect certain regions of the protein (mainly the FKBP12.6 binding domain, covering most $R Y R 2) .{ }^{93}$ Because of the large size of the gene, targeted screening has been used in the past and can potentially miss causative mutations. ${ }^{94}$ Recent studies suggest that mutation location may be associated with severity of the phenotype, suggesting a future role for genetic risk stratification alongside conventional techniques. ${ }^{95}$

Because of the favorable SNR level targeted CPVT genetic testing is recommended for any patient with clinical suspicion of CPVT based on the clinical findings and electrocardiographic phenotype during stress testing. Mutation-specific genetic testing is also recommended for family members and appropriate relatives after the identification of the CPVT-causative mutation in an index case. ${ }^{27}$ Like with LQTS, the 2013 diagnostic guidelines include carriers of a pathogenic mutation as being affected, regardless of clinical features. ${ }^{18}$

Cardiomyopathies. The cardiomyopathies are diseases of the heart muscle associated with mechanical failure of myocardial performance. The American Heart Association (AHA) describes a heterogeneous group of diseases usually exhibiting ventricular hypertrophy or dilatation, caused by a variety of etiologies that frequently are genetic. ${ }^{96}$ They can broadly be divided into HCM, DCM, and ARVC.

HCM, the most common cardiomyopathy, has a prevalence of approximately 1:500 of the general population. $^{96}$ It is characterized by unexplained cardiac hypertrophy, often in an asymmetric septal pattern, but not always. Mutations involving sarcomere proteins and other proteins involved in cardiac contraction are responsible. Familial HCM is mostly $(>90 \%)$ inherited in an autosomal dominant fashion and most mutations involve cardiac $\beta$-myosin heavy chain (MYH7) and cardiac myosin binding protein C (MYBPC3). Genes encoding mitochondrial enzymes have also been identified. ${ }^{97}$ HRS and EHRA guidelines recommend genetic testing after diagnosis, with mutation-specific testing indicated for family members after identification. $^{27}$

In idiopathic DCM, the heart is dilated and impaired leading to symptoms and signs of congestive cardiac failure but without an apparent underlying cause. The estimated prevalence is approximately 1:2500, affecting both adults and children; inherited forms make up to $50 \%$, where there is a family history in one or more relatives. ${ }^{98}$ Mutations in $>30$ genes have been associated with DCM, most following an autosomal dominant inheritance pattern. ${ }^{99}$ The titin gene $(T T N)$ probably accounts for approximately $20 \%$ of cases in recent studies but the high frequency of rare variants has limited the clinical utility of assessing risk; other genes have a low yield. ${ }^{100}$ Extensive or targeted (LMNA and $S C N 5 A$ ) testing is recommended (class I indication) for those patients with significant conduction disease with or without overt DCM as mutations in these genes can indicate an increased risk of SCD. ${ }^{27}$

ARVC is characterized by fibro-fatty replacement of the right and/or left ventricular myocardium with associated risk of SCD because of ventricular arrhythmias. Most cases are inherited in an autosomal dominant pattern with incomplete penetrance and variable expressivity. Its overall prevalence is approximately 1:10000, often presenting between the second and fourth decade of life. ${ }^{101}$ Seven genes have been associated with ARVC: JUP, DSP, PKP2, DSG2, DSC2, TGF 33 , and TMEM43. ${ }^{102}$ HRS and EHRA guidelines suggest that comprehensive or targeted genetic testing can be useful in those that meet existing 2010 task force diagnostic criteria (which include evaluation of right ventricular structure and repolarization abnormalities), but is not helpful in those with an uncertain diagnosis. ${ }^{27}$

\section{FAMILY EVALUATION AND PHENOTYPE TARGETED GENETIC TESTING}

The first study of families of SADS victims reported a limited investigative protocol followed by targeted gene testing in 32 families. ${ }^{103}$ Inherited cardiac disease, mainly LQTS, was diagnosed in $22 \%$ of families although testing of the LQTS genes (KCNQ1, $K C N H 2$, SCN5A, KCNE1, and KCNE2) did not contribute to any of the clinical diagnoses. A followup study of 57 families used more comprehensive clinical assessment and targeted genetic evaluation. ${ }^{70}$ In addition, where available, DNA extracted from formalin-fixed paraffin blocks from 24 SADS cases was used for molecular autopsy of the LQTS genes. Twenty-five families with phenotypic features of cardiac genetic disease underwent targeted mutation analysis. Overall, $53 \%$ of families had features of inherited cardiac disease based on the clinical and genetic evaluation, where $70 \%$ were diagnosed with LQTS or BrS. Genetic evaluation alone contributed to only 1 (2\%) case (identifying a likely LQTS-causing mutation). Other studies have also examined the yield of clinical evaluation and are described in Fig 2. The mean yield of these various studies is $32 \%$ with a range of $18 \%-53 \%$. This variability is very much dependent on the population, the availability of autopsy and expert 


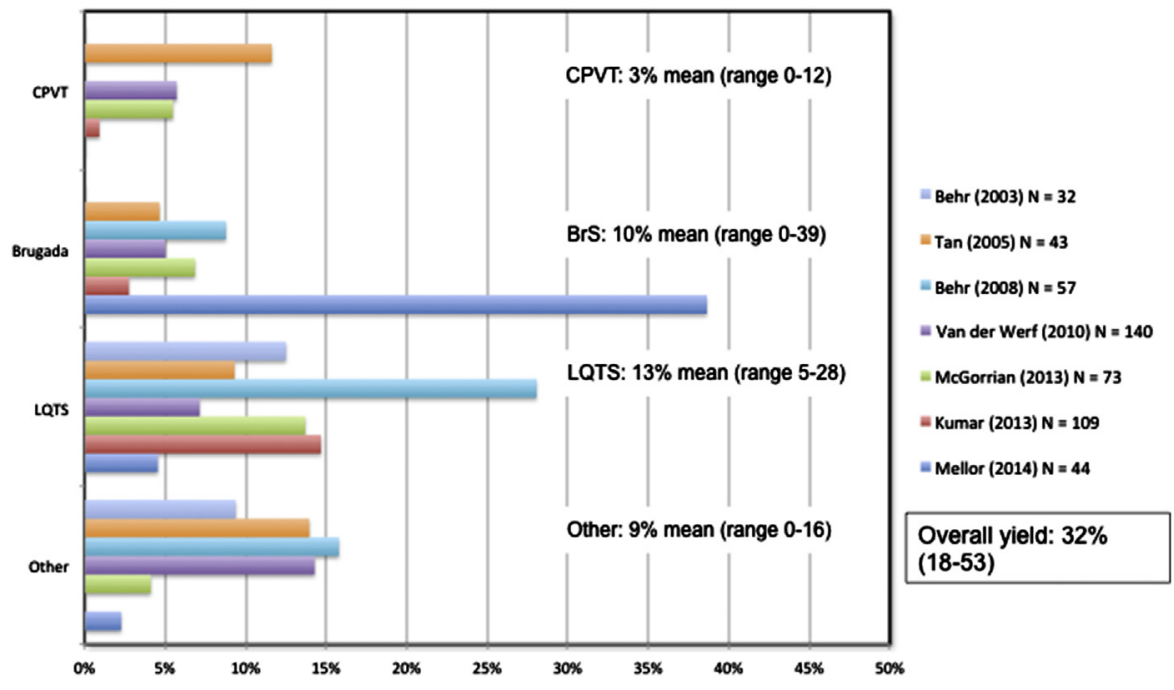

Fig 2. Causes of sudden arrhythmic death syndrome as determined by various studies of familial evaluation. ${ }^{70,103-108} \mathrm{BrS}$, Brugada syndrome; CPVT, catecholaminergic polymorphic ventricular tachycardia; LQTS, long QT syndrome.

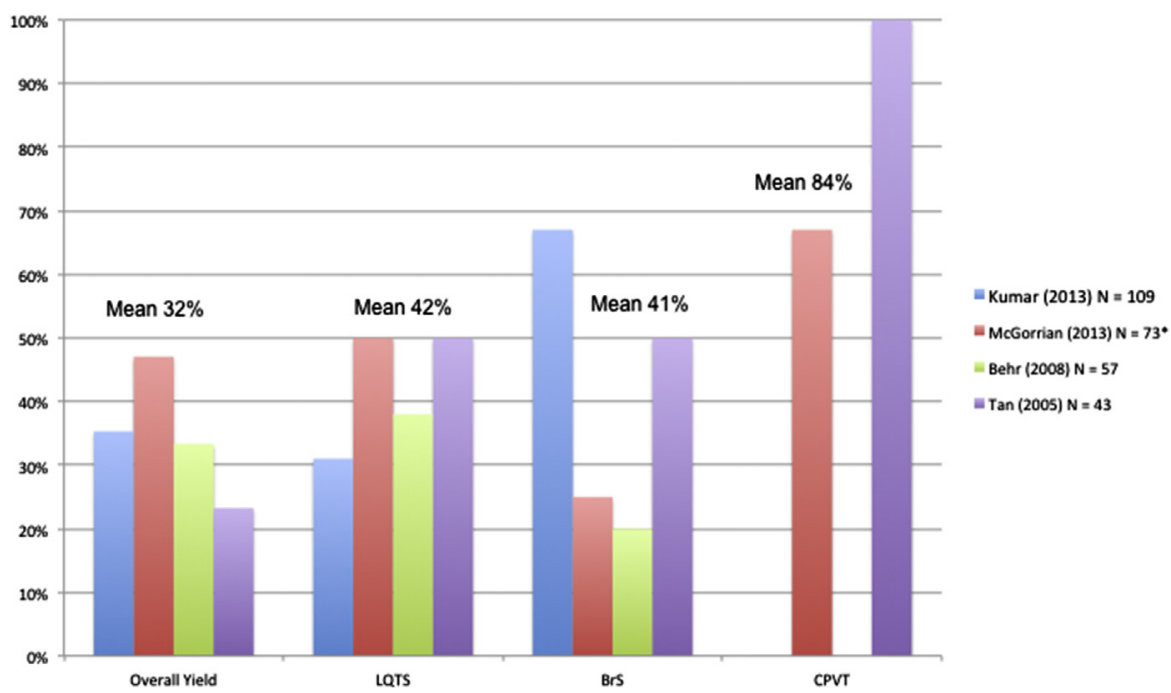

Fig 3. Proportion of molecular diagnoses made in studies of clinical evaluation when testing is targeted to those with a clinical phenotype. ${ }^{70,105-107}$ LQTS, long QT syndrome. *1 CPVT and 1 BrS mutation were exclusively identified via post-mortem genetic testing.

autopsy, and the rigor of the investigative protocol used. Once a diagnosis is made the actual proportion of molecular diagnoses in those with a clinical phenotype ranges from $23 \%-47 \%$ overall (Fig 3).

Clinical role. The importance of systematic and comprehensive clinical and genetic evaluation in SADS families is reinforced by recent guidelines. ${ }^{18}$ Familial evaluation always begins with a detailed analysis of the index case that may give clues to the underlying cause. Pertinent background information includes prior symptoms and clinical encounters (including any previous ECGs) as well as the circumstances of death and pathologic reports. Firstdegree relatives are then offered full clinical cardiological assessment. Relatives with worrisome symptoms such as syncope, seizures, or palpitations are prioritized for assessment and obligate carriers in a pedigree will also be targeted. This includes history and examination, resting 12-lead ECG (with and without high right ventricular leads), echocardiography, exercise, and ambulatory ECGs, and where indicated signal averaged ECG, provocative testing with sodium channel blockers and/or epinephrine, cardiac imaging, and genetic testing. This 
is typically conducted in a multidisciplinary environment with access to genetic counseling in a dedicated inherited cardiac disease clinic. ${ }^{109}$ After comprehensive evaluation, if no abnormalities are detected in first-degree relatives, the risk of future cardiac events related to inherited cardiac disease is generally low. ${ }^{110}$

In the context of familial assessment, gene testing of SADS relatives is targeted to the phenotype identified in the affected members of the family as described in the previous section. Cascade genetic testing is then performed when a positive clinical diagnosis is made in a family member, enabling identification in other relatives by testing for a specific mutation. ${ }^{111}$ Coordination of clinical cardiological evaluation and mutation analysis can also help to clarify whether a VUS is likely to be causative that is segregation analysis.

The lack of $100 \%$ sensitivity of genetic testing must be addressed by appropriate counseling as well as exploration of relatives' concerns and any psychological implications. In 2014, Erskine et al $^{112}$ conducted interviews with 50 individuals who had a personal or family history of an arrhythmic syndrome or SCD. Seventy-four percent pursued genetic testing for LQTS or another channelopathy, motivated by factors such as relieving uncertainty surrounding a potential diagnosis, seeking an explanation for a family member's death, and guiding future medical management. Expectations concerning the scope of genetic testing and individual efficacy in establishing a diagnosis are varied. The main reasons against pursuing testing were fear, denial, and lack of information.

Unfortunately a universal and structured approach to deal with the families of young SCD victims is lacking. Indeed, in many countries no formal local guidance exists for evaluating relatives of SADS cases, and an autopsy is often not required. Van der Werf et al ${ }^{104}$ conducted a community-based intervention study to try to increase autopsy rates of young SCD victims in the Netherlands. Increased awareness in 1 intervention group was promoted via a dedicated helpline for the use of community general practitioners and coroners; information provided by educational meetings and correspondence was also used in another group. The autopsy rate was not significantly improved in either intervention and few families went on to have targeted evaluation in an inherited cardiac disease clinic. This study highlights the difficulties faced in establishing access to suitable services for relatives. Assessment of the cause of death in young SCD cases beyond just exclusion of foul play should be mandatory, as should the onward notification of families to health services. Steps have been taken in Australia, New Zealand, Canada, and the UK, but large gaps in practice remain even in these countries. $^{113-115}$

\section{MOLECULAR AUTOPSY}

Postmortem genetic testing involves the collection of tissue suitable for DNA extraction at autopsy and mutation analysis for specified genes, often described as the "molecular autopsy."

Postmortem sample collection. Postmortem genetic testing has traditionally relied on formalin-fixed paraffin-embedded (FFPE) tissue because of ease of storage and transport. More amenable sample media, such as fresh frozen tissue or EDTA-preserved blood, have not been routinely archived postmortem. In 2008, Carturan et al evaluated different DNA extraction protocols and the feasibility of mutational analysis from archived FFPE tissue. A total of 35 sudden unexpected death syndrome (SUDS) cases were studied; using a number of DNA extraction techniques, nearly one-third of the regions of interest could not be examined. ${ }^{116}$

In case of SADS, HRS guidelines recommend collection of a tissue sample for subsequent DNA analysis. ${ }^{18}$ Tissue samples include heart, liver, spleen, and whole EDTA tube or blood spot testing. The National Association of Medical Examiners suggests circumstances in which such specimens should be saved, detailing DNA preservation standards and appropriate counseling of relatives in the context of SCD. ${ }^{117}$ FFPE should therefore be avoided to allow consistent DNA sampling and more favorable diagnostic yield.

Results in research. The first documented report was in 1999 where LQTS was diagnosed from an autopsy specimen of a 19 year-old girl who died after a neardrowning. ${ }^{118}$ Early work by Tester et al involved mutational analysis of LQTS-associated genes $(K C N Q 1, \quad K C N H 2 \text {, and SCN5A })^{119}$ and RyR2, implicated in CPVT, in 49 SADS cases. ${ }^{120}$ Targeted analysis of 18 exons of RyR2 revealed potential CPVT1-causing mutations in 1 of every 7 cases, whereas the yield in LQTS cases was 1 in 5 (20\%), giving an overall yield of $35 \% .^{27}$

Further research into molecular autopsy has, however, indicated lower yields. In 2011, Skinner et al ${ }^{121}$ performed postmortem genetic testing for LQTS in young sudden unexplained death cases. LQT1-6 gene analysis was performed using direct sequencing or denaturing high-performance liquid chromatography. Thirty-three cases underwent testing, and missense mutations in LQTS genes were found in $15 \%$. A more conservative yield was obtained by Winkel et al, ${ }^{122}$ who examined a young Danish SUDS population of 44 between 2000 


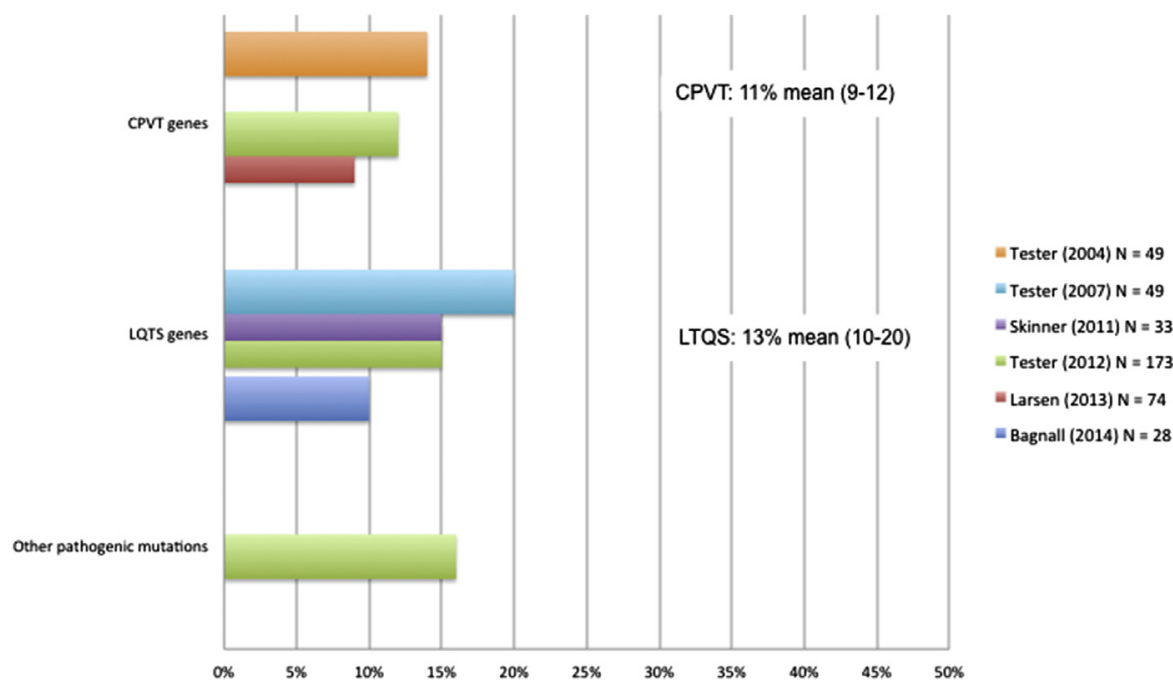

Fig 4. Causes of sudden arrhythmic death syndrome as determined by various molecular autopsy studies. ${ }^{119-121,124-126}$ CPVT, catecholaminergic polymorphic ventricular tachycardia; LQTS, long QT syndrome.

and 2006. KCNQ1, KCNH2, and SCN5A were sequenced; $11 \%$ carried a mutation in at least 1 of the 3 genes. In a UK study, a molecular diagnosis was made in $14 \%$ of 45 cases, and a higher uptake of cascade screening in relatives where a molecular diagnosis had been made at autopsy was also reported. ${ }^{123}$

The yield of testing LQT and CPVT genes was reexamined by Tester et al $^{124}$ more recently in an extended series of 173 autopsy-negative SUDS cases that include their original 49 strong cohort. Forty-five likely pathogenic mutations were identified, but the overall yield (25\%) was lower than their initial cohort. However, the yield was significantly higher $(45 \%)$ in those aged $<50$ years with a family history of premature SCD. Fig 4 describes the yield of molecular autopsy from this and other recent studies. The mean yield of LQTS and CPVT gene testing was $13 \%$ and $11 \%$, respectively, in keeping with more recent conservative estimates.

Clinical role. Thus, if the role for the molecular autopsy is to attempt to make a genetic diagnosis in a family then it cannot supplant clinical evaluation given the lower yield. It may complement evaluation by identifying sporadic mutations and focusing evaluation on any offspring of the victim. It may help to confirm or exclude a putative genetic cause in a family especially if a VUS had been found. Occasionally, it may provide a clear well recognized causative variant and direct family evaluation. However, the SNR in molecular autopsy is already as low as 2.25 for the major LQTS and CPVT genes because of the relatively low yields and frequency of rare variation in the general population (see Fig 1). It is therefore not a stand-alone tool at this time. Nonetheless molecular autopsy may have implications for the prevention of additional deaths in other relatives, and HRS and EHRA guidelines currently recommend genetic testing if circumstantial evidence points toward a clinical diagnosis of LQTS or CPVT ${ }^{70}$ (Fig 1). This has been reinforced by the more recent clinical testing guidelines that state that an arrhythmia syndrome focused gene panel can be useful. ${ }^{18}$

\section{NEXT-GENERATION SEQUENCING AND THE FUTURE}

Genetic testing for the channelopathies has traditionally involved Sanger sequencing for single gene mutations. ${ }^{127}$ This method is limited by potential scalability, as more genes with susceptibility to channelopathy have been identified. Advances in technology, massive parallel sequencing or next-generation sequencing, have led to the ability to simultaneously sequence protein coding exons of all genes nucleotide by nucleotide ("the exome," which is approximately $1 \%$ of the genome) from much smaller quantities of DNA. ${ }^{128}$

Bagnall et $\mathrm{al}^{125}$ performed exome sequencing on a subgroup of 28 SUDS cases referred for autopsy in Australia between 2005 and 2009. Three rare variants were discovered in the 3 most common LQTS genes when a narrow panel of the 4 major genes $(K C N Q 1$, $K C N H 2, S C N 5 A$, and RYR2) was studied. The scope of the molecular autopsy was also expanded to include a wider selection of $>70$ arrhythmia and cardiomyopathy genes, subsequently revealing a variant in the $C A C$ $N A 1 C$ gene of a 20 year-old man who died in his sleep. This variant had previously been identified in a LQTS family, ${ }^{129}$ highlighting that screening additional genes may offer causality beyond the "usual suspects." Unfortunately two-thirds of the other putative mutations that were identified were VUSs. 


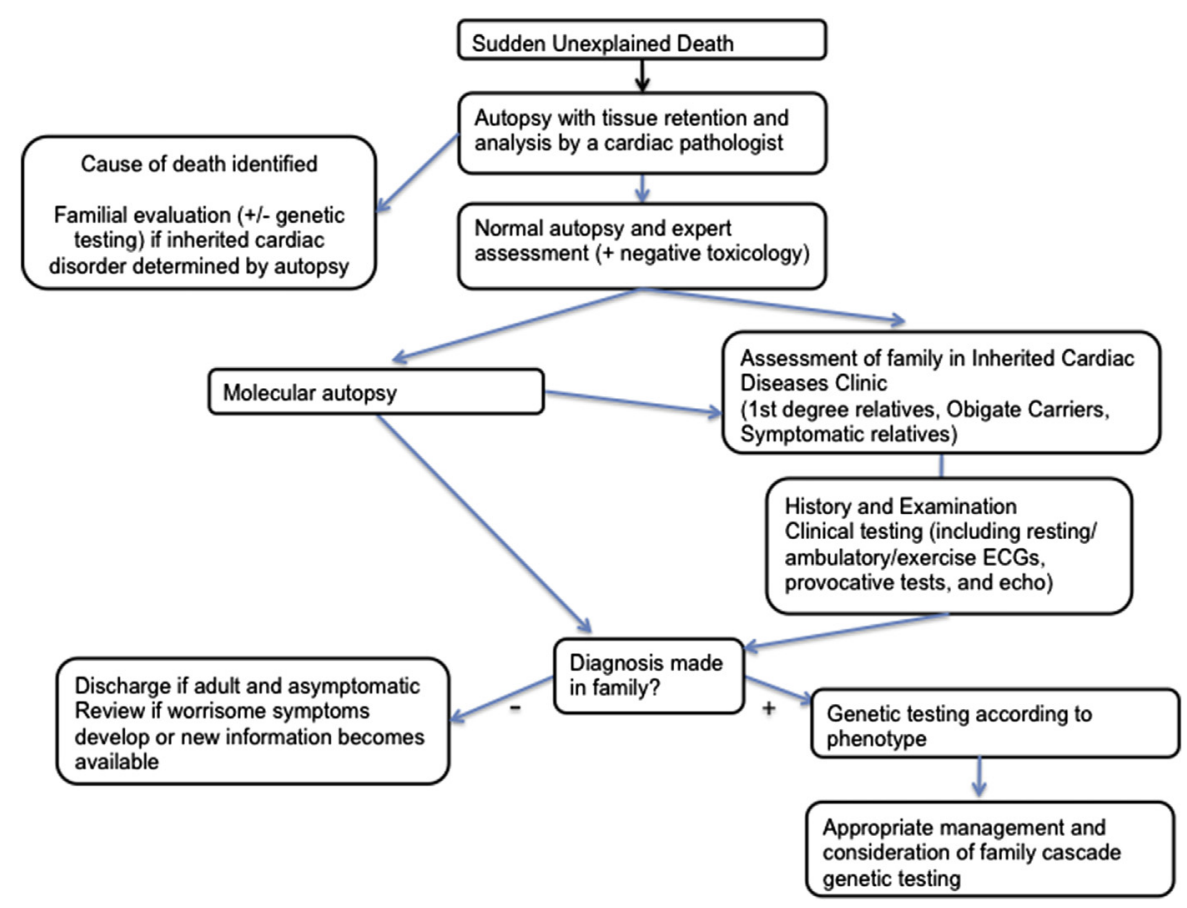

Fig 5. Recommended diagnostic pathway after a sudden unexplained death (adapted from Wong and Behr ${ }^{130}$ ). ECG, electrocardiogram.

This highlights the concern over increasing gene panel sizes. The SNR will become even lower for the expanded "next-generation" arrhythmia syndrome and cardiac genetic disease panels because of the enhanced background variation and minimal increase in yield. The family context is currently the only way to extract additional value from the high yield of VUSs by molecular autopsy. This situation will only improve when more is understood about how to assess the likely functional effects of mutations detected in these disorders.

\section{CONCLUSIONS}

The molecular autopsy can only occasionally diagnose disease in an index case and direct subsequent family evaluation. Because of methodological issues surrounding determination of variant pathogenicity, the comprehensive next-generation sequencing panel will have to complement careful phenotypic evaluation of family members to inform a targeted genotyping strategy (see Fig 5). Indeed, the utility of genetic testing is only really appreciated in such a context and represents the best chance of developing clinically meaningful results. Only once robust methods are in place for assessing the pathogenicity or disease susceptibility of putative mutations from a large range of potential genetic causes can the molecular autopsy be a truly diagnostic tool. In the interim most of its clinical utility will be provided by analyzing the 4 major LQTS, BrS, and CPVT genes that we already know and understand best.

\section{ACKNOWLEDGMENTS}

Conflicts of Interest: All authors have read the journal's authorship agreement and policy on disclosure of potential conflicts of interest and have none to declare.

There are no financial or personal relationships with organizations that could potentially be perceived as influencing the research. The manuscript has been read and approved by all the named authors.

\section{REFERENCES}

1. Nichol G, Thomas E, Callaway CW, et al. Regional variation in out-of-hospital cardiac arrest incidence and outcome. JAMA 2008;300:1423-31.

2. Chugh SS, Jui J, Gunson K, et al. Current burden of sudden cardiac death: multiple source surveillance versus retrospective death certificate-based review in a large U.S. Community. J Am Coll Cardiol 2004;44:1268-75.

3. Byrne R, Constant O, Smyth Y, et al. Multiple source surveillance incidence and aetiology of out-of-hospital sudden cardiac death in a rural population in the west of Ireland. Eur Heart J 2008;29:1418-23.

4. Engelstein ED, Zipes DP. Sudden cardiac death. In: Alexander RW, Schlant RC, Fuster V, eds. The heart, arteries and veins. New York, NY: McGraw-Hill, 1998:1081-112.

5. Myerburg RJ. Cardiac arrest and sudden cardiac death' in heart disease: a textbook of cardiovascular medicine. 7th ed. Philadelphia: WB Saunders, 2005. 
6. NICE Technology Appraisal—implantable cardioverter defibrillators and cardiac resynchronisation therapy for arrhythmias and heart failure. 2014. Available at: http://www.nice.org.uk/ guidance/ta314/chapter/2-clinical-need-and-practice. Accessed September 2014.

7. Winkel BG. Sudden cardiac death in young Danes. Dan Med J 2012;59:B4403.

8. Eckart RE, Scoville SL, Campbell CL, et al. Sudden death in young adults: a 25-year review of autopsies in military recruits. Ann Intern Med 2004;141:829-34.

9. Puranik R, Chow CK, Duflou JA, Kilborn MJ, McGuire MA. Sudden death in the young. Heart Rhythm 2005;2:1277-82.

10. Risgaard B, Winkel BG, Jabbari R, et al. Burden of sudden cardiac death in persons aged 1 to 49 years: nationwide study in Denmark. Circ Arrhythm Electrophysiol 2014;7:205-11.

11. Corrado D, Basso C, Thiene G. Sudden cardiac death in young people with apparently normal heart. Cardiovasc Res 2001;50: 399-408.

12. Corrado D, Fontaine G, Marcus FI, et al. Arrhythmogenic right ventricular dysplasia/cardiomyopathy: need for an international registry. Study Group on Arrhythmogenic Right Ventricular Dysplasia/Cardiomyopathy of the Working Groups on Myocardial and Pericardial Disease and Arrhythmias of the European Society of Cardiology and of the Scientific Council on Cardiomyopathies of the World Heart Federation. Circulation 2000; 101:E101-6.

13. Maron BJ, Doerer JJ, Haas TS, Tierney DM, Mueller FO. Sudden deaths in young competitive athletes: analysis of 1866 deaths in the United States, 1980-2006. Circulation 2009;119: 1085-92.

14. Papadakis M, Sharma S, Cox C, Sheppard MN, Panoulas VF, Behr ER. The magnitude of sudden cardiac death in the young: a death certificate-based review in England and Wales. Europace 2009; 11:1353-8.

15. Tester DJ, Medeiros-Domingo A, Will ML, Ackerman MJ. Unexplained drownings and the cardiac channelopathies: a molecular autopsy series. Mayo Clin Proc 2011;86:941-7.

16. Raji H, Behr ER. Unexplained sudden death, focussing on genetics and family phenotyping. Curr Opin Cardiol 2013;28: $19-25$.

17. Sandorfi G, Clemens B, Csanadi Z. Electrical storm in the brain and in the heart: epilepsy and Brugada syndrome. Mayo Clin Proc 2013:88:1167-73.

18. Priori SG, Wilde AA, Horie M, et al. HRS/EHRA/APHRS expert consensus statement on the diagnosis and management of patients with inherited primary arrhythmia syndromes: document endorsed by HRS, EHRA, and APHRS in May 2013 and by ACCF, AHA, PACES, and AEPC in June 2013. Heart Rhythm 2013; 10:1932-63.

19. Papadakis M, Hariharan R, Behr ER, et al. Sudden cardiac death with autopsy findings of uncertain significance. Circ Arrhythm Electrophysiol 2013;6:588-96.

20. de Noronha SV, Behr ER, Papadakis M, et al. The importance of specialist cardiac histopathological examination in the investigation of young sudden cardiac deaths. Europace 2014;16: 899-907.

21. Trans-Tasman Response Against Sudden Death in the Young (TRAGADY). Post-mortem in sudden unexpected death in the young: guidelines on autopsy practice. 2008. Available at: https://www.cidg.org/webcontent/LinkClick.aspx? fileticket=D O9YIQWqegI\%3D\&tabid=161. Accessed June 5, 2015.

22. Office of the Chief Coroner for Ontario. Guidelines for the investigation of sudden cardiac death. Memo \#08-01. Available at: http://nsgc.org/d/do/978. Accessed June 5, 2015.
23. Sudden Death in the Young Case Registry. University of Michigan. National Heart, Lung, and Blood Institute (NHLBI), the National Institute of Neurological Disorders and Stroke (NINDS), and the Centers for Disease Control and Prevention (CDC). Available at: http://www.nhlbi.nih.gov/news/spotlight/factsheet/frequently-asked-questions-about-sudden-death-young-ca se-registry. Accessed June 5, 2015.

24. Coronary Heart Disease National Service Framework, . Chapter 8. Arrhythmias and sudden cardiac death. London: Department of Health, 2005.

25. Wilde AA, Behr ER. Genetic testing for inherited cardiac disease. Nat Rev Cardiol 2013;10:571-83.

26. Landstrom AP, Ackerman MJ. The Achilles' heel of cardiovascular genetic testing: distinguishing pathogenic mutations from background genetic noise. Clin Pharmacol Ther 2011;90:496-9.

27. Ackermann MJ, Priori SG, Willems S, et al. HRS/EHRA expert consensus statement on the state of genetic testing for the channelopathies and cardiomyopathies. Europace 2011;13: 1077-109.

28. Willerson J, Cohn J, Wellens H, Holmes D. Cardiovascular medicine. 3rd ed. New York: Springer, 2007. ISBN-10: 1846281881 P2592.

29. Tester DJ, Ackerman MJ. Genetic testing for potentially lethal, highly treatable inherited cardiomyopathies/channelopathies in clinical practice. Circulation 2011;123:1021-37.

30. Exome Aggregation Consortium (ExAC), Cambridge, MA. Available at: http://exac.broadinstitute.org. Accessed June 3, 2015.

31. Tfelt-Hansen J, Jespersen T, Hofman-Bang J, et al. Ventricular tachycardia in a Brugada syndrome patient caused by a novel deletion in SCN5A. Can J Cardiol 2009;25:156-60.

32. Herman DS, Lam L, Taylor MR, et al. Truncations of titin causing dilated cardiomyopathy. N Engl J Med 2012;366: 619-28.

33. Roberts AM, Ware JS, Herman DS, et al. Integrated allelic, transcriptional, and phenomic dissection of the cardiac effects of titin truncations in health and disease. Sci Transl Med 2015;7: 270ra6.

34. Jabbari J, Jabbari R, Nielsen MW, et al. New exome data question the pathogenicity of genetic variants previously associated with catecholaminergic polymorphic ventricular tachycardia. Circ Cardiovasc Genet 2013;6:481-9.

35. Refsgaard L, Holst AG, Sadjadieh G, Hauns $\varnothing$ S, Nielsen JB, Olesen MS. High prevalence of genetic variants previously associated with LQT syndrome in new exome data. Eur J Hum Genet 2012;20:905-8.

36. Norton N, Robertson PD, Rieder MJ, et al. Evaluating pathogenicity of rare variants from dilated cardiomyopathy in the exome era. Circ Cardiovasc Genet 2012;5:167-74.

37. Bell CJ, Dinwiddie DL, Miller NA, et al. Carrier testing for severe childhood recessive diseases by next-generation sequencing. Sci Transl Med 2011;3:65ra4.

38. Grantham R. Amino acid difference formula to help explain protein evolution. Science 1974;185:862-4.

39. Giudicessi JR, Kapplinger JD, Tester DJ, et al. Phylogenetic and physicochemical analyses enhance the classification of rare nonsynonymous single nucleotide variants in type 1 and 2 long-QT syndrome. Circ Cardiovasc Genet 2012;5:519-28.

40. Kapplinger JD, Giudicessi JR, Ye D, et al. Enhanced classification of Brugada syndrome- and long QT syndrome-associated genetic variants in the SCN5A-encoded Nav1.5 cardiac sodium channel. Circ Cardiovasc Genet 2015 [Epub ahead of print].

41. Campuzano O, Allegue C, Fernandez A, Iglesias A, Brugada R. Determining the pathogenicity of genetic variants associated with cardiac channelopathies. Sci Rep 2015;5:7953. 
42. Itoh H, Shimizu W, Hayashi K, et al. Long QT syndrome with compound mutations is associated with a more severe phenotype: a Japanese multicenter study. Heart Rhythm 2010;7: 1411-8.

43. Crotti L, Marcou CA, Tester DJ, et al. Spectrum and prevalence of mutations involving BrS1-12-susceptibility genes in a cohort of unrelated patients referred for Brugada syndrome genetic testing: implications for genetic testing. J Am Coll Cardiol 2012;60:1410-8.

44. Burashnikov E, Pfeiffer R, Barajas-Martinez H, et al. Mutations in the cardiac L-type calcium channel associated with inherited J-wave syndromes and sudden cardiac death. Heart Rhythm 2010;7:1872-82.

45. Antzelevitch C, Pollevick GD, Cordeiro JM, et al. Loss-of-function mutations in the cardiac calcium channel underlie a new clinical entity characterized by ST-segment elevation, short QT intervals, and sudden cardiac death. Circulation 2007;115: 442-9.

46. Ueda K, Hirano Y, Higashiuesato Y, et al. Role of HCN4 channel in preventing ventricular arrhythmia. J Hum Genet 2009;54: $115-21$.

47. Ishikawa T, Sato A, Marcou CA, et al. A novel disease gene for Brugada syndrome: sarcolemmal membrane-associated protein gene mutations impair intracellular trafficking of hNav1.5. Circ Arrhythm Electrophysiol 2012;5:1098-107.

48. Hedley PL, Jørgensen P, Schlamowitz S, Wangari R, MoolmanSmook J, Brink PA. The genetic basis of long QT and short QT syndromes: a mutation update. Hum Mutat 2009;30:1486-511.

49. Yang Y, Liang B, Liu J, et al. Identification of a Kir3.4 mutation in congenital long QT syndrome. Am J Hum Genet 2010;86: 872-80.

50. Crotti L, Johnson CN, Graf E, et al. Calmodulin mutations associated with recurrent cardiac arrest in infants. Circulation 2013 127:1009-17.

51. Priori SG, Napolitano C, Memmi M, et al. Clinical and molecular characterization of patients with catecholaminergic polymorphic ventricular tachycardia. Circulation 2002;106:69-74.

52. Lahat H, Pras E, Olender T, et al. A missense mutation in a highly conserved region of CASQ2 is associated with autosomal recessive catecholamine-induced polymorphic ventricular tachycardia in Bedouin families from Israel. Am J Hum Genet 2001;69:1378-84.

53. Roux-Buisson N, Cacheux M, Fourest-Lieuvin A, et al. Absence of triadin, a protein of the calcium release complex, is responsible for cardiac arrhythmia with sudden death in human. Hum Mol Genet 2012;21:2759-67.

54. Nyegaard M, Overgaard MT, Søndergaard MT, et al. Mutations in calmodulin cause ventricular tachycardia and sudden cardiac death. Am J Hum Genet 2012;91:703-12.

55. Bellocq C, van Ginneken AC, Bezzina CR, et al. Mutation in the KCNQ1 gene leading to the short QT-interval syndrome. Circulation 2004;109:2394-7.

56. Bartos DC, Anderson JB, Bastiaenen R, et al. A KCNQ1 mutation causes a high penetrance for familial atrial fibrillation. J Cardiovasc Electrophysiol 2013;24:562-9.

57. Priori SG, Pandit SV, Rivolta I, et al. A novel form of short QT syndrome (SQT3) is caused by a mutation in the KCNJ2 gene. Circ Res 2005;96:800-7.

58. Yang Y, Xia M, Jin Q, et al. Identification of a KCNE2 gain-offunction mutation in patients with familial atrial fibrillation. Am J Hum Genet 2004; 75:899-905.

59. Xia M, Jin Q, Bendahhou S, et al. A Kir2.1 gain-of-function mutation underlies familial atrial fibrillation. Biochem Biophys Res Commun 2005;332:1012-9.
60. Medeiros-Domingo A, Tan BH, Crotti L, et al. Gain-of-function mutation S422L in the KCNJ8-encoded cardiac K(ATP) channel Kir6.1 as a pathogenic substrate for J-wave syndromes. Heart Rhythm 2010;7:1466-71.

61. Haïssaguerre M, Chatel S, Sacher F, et al. Ventricular fibrillation with prominent early repolarization associated with a rare variant of KCNJ8/KATP channel. J Cardiovasc Electrophysiol 2009;20:93-8.

62. Alders M, Koopmann TT, Christiaans I, et al. Haplotype-sharing analysis implicates chromosome 7q36 harboring DPP6 in familial idiopathic ventricular fibrillation. Am J Hum Genet 2009;84: 468-76.

63. Schulze-Bahr E, Neu A, Friederich P, et al. Pacemaker channel dysfunction in a patient with sinus node disease. J Clin Invest 2003;111:1537-45.

64. Schott JJ, Alshinawi C, Kyndt F, et al. Cardiac conduction defects associate with mutations in SCN5A. Nat Genet 1999;23: $20-1$

65. Watanabe H, Nogami A, Ohkubo K, et al. Electrocardiographic characteristics and SCN5A mutations in idiopathic ventricular fibrillation associated with early repolarization. Circ Arrhythm Electrophysiol 2011;4:874-81.

66. Benson DW, Wang DW, Dyment M, et al. Congenital sick sinus syndrome caused by recessive mutations in the cardiac sodium channel gene (SCN5A). J Clin Invest 2003;112:1019-28.

67. Makita N, Behr E, Shimizu W, et al. The E1784K mutation in SCN5A is associated with mixed clinical phenotype of type 3 long QT syndrome. J Clin Invest 2008;118:2219-29.

68. Bezzina C, Veldkamp MW, van Den Berg MP, et al. A single $\mathrm{Na}(+)$ channel mutation causing both long-QT and Brugada syndromes. Circ Res 1999;85:1206-13.

69. Laurent G, Saal S, Amarouch MY, et al. Multifocal ectopic Purkinje-related premature contractions: a new SCN5Arelated cardiac channelopathy. J Am Coll Cardiol 2012;60: 144-56.

70. Behr ER, Dalageorgou C, Christiansen M, et al. Sudden arrhythmic death syndrome: familial evaluation identifies inheritable heart disease in the majority of families. Eur Heart J 2008; 29:1670-80.

71. Schwartz PJ, Stramba-Badiale M, Crotti L, et al. Prevalence of the congenital long-QT syndrome. Circulation 2009;120: $1761-7$.

72. Mizusawa Y, Horie M, Wilde AA. Genetic and clinical advances in congenital long QT syndrome. Circ J 2014;78:2827-33.

73. Hedley PL, Kanters JK, Dembic M, et al. The role of CAV3 in long-QT syndrome: clinical and functional assessment of a caveolin-3/Kv11.1 double heterozygote versus caveolin-3 single heterozygote. Circ Cardiovasc Genet 2013;6:452-61.

74. Wilde A, Antzelevitch C, Borggrefe M, et al. Proposed diagnostic criteria for the Brugada syndrome. Eur Heart J 2002;23: $1648-54$

75. Matsuo K, Kurita T, Inagaki M, et al. The circadian pattern of the development of ventricular fibrillation in patients with Brugada syndrome. Eur Heart J 1999;20:465-70.

76. Amin AS, Klemens CA, Verkerk AO, et al. Fever-triggered ventricular arrhythmias in Brugada syndrome and type 2 long-QT syndrome. Neth Heart J 2010;18:165-9.

77. Wolpert C, Echternach C, Veltmann C, et al. Intravenous drug challenge using flecainide and ajmaline in patients with Brugada syndrome. Heart Rhythm 2005;2:254-60.

78. Raju H, Papadakis M, Govindan M, et al. Low prevalence of risk markers in cases of sudden death due to Brugada syndrome: relevance to risk stratification in Brugada syndrome. J Am Coll Cardiol 2011;57:2340-5. 
79. Kamakura S. Epidemiology of Brugada syndrome in Japan and the rest of the world. J Arrhythmia 2013;29:52-5.

80. Gray B, Semsarian C, Sy RW. Brugada syndrome: a heterogeneous disease with a common ECG phenotype? J Cardiovasc Electrophysiol 2014:25:450-6.

81. Schulze-Bahr E, Eckardt L, Breithardt G, et al. Sodium channel gene (SCN5A) mutations in 44 index patients with Brugada syndrome: different incidences in familial and sporadic disease. Hum Mutat 2005;26:61.

82. Bezzina CR, Barc J, Mizusawa Y, et al. Common variants at SCN5A-SCN10A and HEY2 are associated with Brugada syndrome, a rare disease with high risk of sudden cardiac death. Nat Genet 2013;45:1044-9.

83. Antzelevitch C, Brugada P, Borggrefe M, et al. Brugada syndrome: report of the Second Consensus Conference Endorsed by the Heart Rhythm Society and the European Heart Rhythm Association. Circulation 2005;111:659-70.

84. Kapplinger D, Tester DJ, Alders M, et al. An international compendium of mutations in the SCN5A-encoded cardiac sodium channel in patients referred for Brugada syndrome genetic testing. Heart Rhythm 2010;7:33-46.

85. Bezzina CR, Rook MB, Wilde AA. Cardiac sodium channel and inherited arrhythmia syndromes. Cardiovasc Res 2001;49: 257-71.

86. Probst V, Wilde AA, Barc J, et al. SCN5A mutations and the role of genetic background in the pathophysiology of Brugada syndrome. Circ Cardiovasc Genet 2009;2:552-7.

87. Hu D, Barajas-Martínez H, Pfeiffer R, et al. Mutations in SCN10A are responsible for a large fraction of cases of Brugada syndrome. J Am Coll Cardiol 2014;64:66-79.

88. Reid DS, Tynan M, Braidwood L, Fitzgerald GR. Bidirectional tachycardia in a child: a study using His bundle electrography. Br Heart J 1975;37:339-44.

89. Napolitano C, Bloise R, Memmi M, Priori S. Clinical utility gene card for: catecholaminergic polymorphic ventricular tachycardia (CPVT). Eur J Hum Genet 2014;22 http://dx.doi.org/10.1 038/ejhg.2013.55. published online April 3, 2013.

90. Kumar D, Elliot P. Principles and practice of clinical cardiovascular genetics. US: Oxford University Press, 2010:P257. ISBN 978-0-19-536895-6.

91. Bastiaenen R, Behr E. Sudden death and ion channel disease: pathophysiology and implications for management. Heart 2011;97:1365-72

92. Napolitano C, Priori SG, Bloise R. Catecholaminergic polymorphic ventricular tachycardia. In: Pagon RA, Adam MP, Ardinger HH, et al., eds. GeneReviews ${ }^{\circledR}$ [Internet]. Seattle, WA: University of Washington, Seattle:1993-2014. Available at: http://www.ncbi.nlm.nih.gov/books/NBK1289/; 2004. Accessed March 6, 2014.

93. George CH, Jundi H, Thomas NL, Fry DL, Lai FA. Ryanodine receptors and ventricular arrhythmias: emerging trends in mutations, mechanisms and therapies. J Mol Cell Cardiol 2007;42: $34-50$.

94. Medeiros-Domingo A, Bhuiyan ZA, Tester DJ, et al. The RYR2-encoded ryanodine receptor/calcium release channel in patients diagnosed previously with either catecholaminergic polymorphic ventricular tachycardia or genotype negative, exercise-induced long QT syndrome: a comprehensive open reading frame mutational analysis. J Am Coll Cardiol 2009;54: 2065-74.

95. Van der Werf C, Nederend I, Hofman N, et al. Familial evaluation in catecholaminergic polymorphic ventricular tachycardia: disease penetrance and expression in cardiac ryanodine receptor mutation-carrying relatives. Circ Arrhythm Electrophysiol 2012; 5:748-56.

96. Maron BJ, Towbin JA, Thiene G, et al. Contemporary definitions and classification of the cardiomyopathies: an American Heart Association Scientific Statement from the Council on Clinical Cardiology, Heart Failure and Transplantation Committee; Quality of Care and Outcomes Research and Functional Genomics and Translational Biology Interdisciplinary Working Groups; and Council on Epidemiology and Prevention. Circulation 2006;113:1807-16.

97. Roma-Rodrigues C, Fernandes A. Genetics of hypertrophic cardiomyopathy: advances and pitfalls in molecular diagnosis and therapy. Appl Clin Genet 2014;7:195-208.

98. Sheppard M. Practical cardiovascular pathology. 2nd ed. US CRC Press, 2011. ISBN-10: 0340981938.

99. van Spaendonck-Zwarts KY, van Rijsingen IA, van den Berg MP et al. Genetic analysis in 418 index patients with idiopathic dilated cardiomyopathy: overview of 10 years' experience. Eur J Heart Fail 2013;15:628-36.

100. Mestroni L, Taylor M. Genetics and genetic testing of dilated cardiomyopathy: a new perspective. Discov Med 2013;15: 43-9.

101. Sen-Chowdhry S, Morgan RD, Chambers JC, McKenna WJ. Arrhythmogenic cardiomyopathy: etiology, diagnosis, and treatment. Annu Rev Med 2010;61:233-53.

102. Marcus FI, McKenna WJ, Sherrill D, et al. Diagnosis of arrhythmogenic right ventricular cardiomyopathy/dysplasia. Circulation 2010;121:1533-41.

103. Behr E, Wood DA, Wright M, et al. Cardiological assessment of first-degree relatives in sudden arrhythmic death syndrome. Lancet 2003;362:1457-9.

104. Van der Werf C, Hofman N, Tan HL, et al. Diagnostic yield in sudden unexplained death and aborted cardiac arrest in the young: the experience of a tertiary referral center in The Netherlands. Heart Rhythm 2010;7:1383-9.

105. Tan HL, Hofman N, van Langen IM, van der Wal AC, Wilde AA. Sudden unexplained death: heritability and diagnostic yield of cardiological and genetic examination in surviving relatives. Circulation 2005;112:207-13.

106. McGorrian C, Constant O, Harper N, et al. Family-based cardiac screening in relatives of victims of sudden arrhythmic death syndrome. Europace 2013;15:1050-8.

107. Kumar S, Peters S, Thompson T, et al. Familial cardiological and targeted genetic evaluation: low yield in sudden unexplained death and high yield in unexplained cardiac arrest syndromes. Heart Rhythm 2013;10:1653-60.

108. Mellor G, Raju H, de Noronha SV, et al. Clinical characteristics and circumstances of death in the sudden arrhythmic death syndrome. Circ Arrhythm Electrophysiol 2014;7:1078-83.

109. Kauferstein S, Kiehne N, Jenewein T, et al. Genetic analysis of sudden unexplained death: a multidisciplinary approach. Forensic Sci Int 2013;229:122-7.

110. van der Werf C, Stiekema L, Tan HL, et al. Low rate of cardiac events in first-degree relatives of diagnosis-negative young sudden unexplained death syndrome victims during follow-up. Heart Rhythm 2014;11:1728-32.

111. Garratt CJ, Elliott P, Behr ER, et al. Clinical indications for genetic testing in familial sudden cardiac death syndromes: an HRUK position statement. Heart 2008;94:502-7.

112. Erskine KE, Hidayatallah NZ, Walsh CA, et al. Motivation to pursue genetic testing in individuals with a personal or family history of cardiac events or sudden cardiac death. J Genet Couns 2014:23:849-59. 
113. UK Department of Health. National Service Framework for Coronary Heart Disease-Chapter 8: arrhythmias and sudden cardiac death. 2005. Available at: http://webarchive.nationalarchi ves.gov.uk/20130107105354/http://www.dh.gov.uk/prod_consu m_dh/groups/dh_digitalassets/@dh/@en/documents/digitalasse t/dh_4105280.pdf. Accessed June 4, 2016.

114. Pilmer CM, Porter B, Kirsh JA, et al. Scope and nature of sudden cardiac death before age 40 in Ontario: a report from the cardiac death advisory committee of the office of the chief coroner. Heart Rhythm 2013;10:517-23.

115. Skinner JR, Duflou JA, Semsarian C. Reducing sudden death in young people in Australia and New Zealand: the TRAGADY initiative. Med J Aust 2008;189:539-40.

116. Carturan E, Tester DJ, Brost BC, Basso C, Thiene G, Ackerman MJ. Postmortem genetic testing for conventional autopsy-negative sudden unexplained death: an evaluation of different DNA extraction protocols and the feasibility of mutational analysis from archival paraffin-embedded heart tissue. Am J Clin Pathol 2008;129:391-7.

117. Middleton O, Baxter S, Demo E, et al. National Association of Medical Examiners Position Paper: retaining postmortem samples for genetic testing. Acad Forensic Pathol 2013;3:191-4.

118. Ackerman MJ, Tester DJ, Coburn JP, Edwards WD. Molecular diagnosis of the inherited long-QT syndrome in a woman who died after near-drowning. N Engl J Med 1999;341:1121-5.

119. Tester DJ, Ackerman MJ. Postmortem long QT syndrome genetic testing for sudden unexplained death in the young. J Am Coll Cardiol 2007:49:240-6.

120. Tester DJ, Spoon DB, Valdivia HH, Makielski JC, Ackerman MJ. Targeted mutational analysis of the RyR2encoded cardiac ryanodine receptor in sudden unexplained death: a molecular autopsy of 49 medical examiner/coroner's cases. Mayo Clin Proc 2004;79:1380-4.

121. Skinner JR, Crawford J, Smith W, et al. Prospective, population-based long QT molecular autopsy study of postmor- tem negative sudden death in 1 to 40 year olds. Heart Rhythm 2011;8:412-9.

122. Winkel B, Larsen M, Olesen M, Tfelt-Hansen J, Banner J. The prevalence of mutations in KCNQ1, $\mathrm{KCNH} 2$, and SCN5A in an unselected national cohort of young sudden unexplained death cases. J Cardiovasc Electrophysiol 2012;23: 1092-8.

123. Dean J, Cann F, Corbett M, et al. Molecular autopsy for sudden cardiac death-outcome of a practical approach. Heart Lung Circ 2014;23:e3.

124. Tester DJ, Medeiros-Domingo A, Will ML, Haglund CM, Ackerman MJ. Cardiac channel molecular autopsy: insights from 173 consecutive cases of autopsy-negative sudden unexplained death referred for postmortem genetic testing. Mayo Clin Proc 2012;87:524-39.

125. Bagnall R, Das KJ, Duflou J, Semsarian C. Exome analysisbased molecular autopsy in cases of sudden unexplained death in the young. Heart Rhythm 2014;11:655-62.

126. Larsen MK, Berge KE, Leren TP, et al. Postmortem genetic testing of the ryanodine receptor 2 (RYR2) gene in a cohort of sudden unexplained death cases. Int J Legal Med 2013;127: $139-44$.

127. Churko J, Mantalas G, Synder M, Wu J. Overview of high throughput sequencing technologies to elucidate molecular pathways in cardiovascular diseases. Circ Res 2013;112:1613-23.

128. Chugh SS, Huertas-Vazquez A. Inherited arrhythmia syndromes: exome sequencing opens a new door to diagnosis. J Am Coll Cardiol 2014;63:267-8.

129. Laish-Farkash A, Nof E, Luria D, et al. Incessant bidirectional ventricular tachycardia as the presenting arrhythmia of Andersen-Tawil syndrome in two families. J Interv Card Electrophysiol 2009;24:213-7. Special Abstract Issue of ECAS.

130. Wong LC, Behr ER. Sudden unexplained death in infants and children: the role of undiagnosed inherited cardiac conditions. Europace 2014c;16:1706-13. 